\title{
CORRIGENDA
}

\section{Hypogonadism is associated with overt depression symptoms in men with erectile dysfunction}

\author{
AA Makhlouf, MA Mohamed, AD Seftel and C Neiderberger \\ International Journal of Impotence Research (2008) 20, 229; doi:10.1038/sj.ijir.3901616
}

Correction to:

International Journal of Impotence Research (2007) 19, doi:10.1038/sj.ijir.3901576.
Following the publication of this article, it was discovered that the name of the last author, Dr C Niederberger, was misspelled. The correct spelling is C Niederberger.

\section{Long-term efficacy and compliance of MUSE for erectile dysfunction following radical prostatectomy: SHIM (IIEF-5) analysis}

R Raina, A Agarwal, S Ausmundson, D Mansour and CD Zippe

International Journal of Impotence Research (2008) 20, 229; doi:10.1038/sj.ijir.3901621

Correction to: International Journal of Impotence Research (2005) 17, 86-90. doi:10.1038/sj.ijir. 3901284; published online 4 November 2004 (http://www.nature.com/ijir/journal/v17/n1/full/ 3901284a.html)

Since the publication of the above paper, the authors indicated that Carlumandarlo EB Zaramo should be included as the third author (and affiliated with the Glickman Urological Institute, Cleveland Clinic Foundation, Cleveland, OH, USA). The correct order of authors should be as follows:

R Raina, A Agarwal, CEB Zaramo, S Ausmundson, D Mansour and CD Zippe 